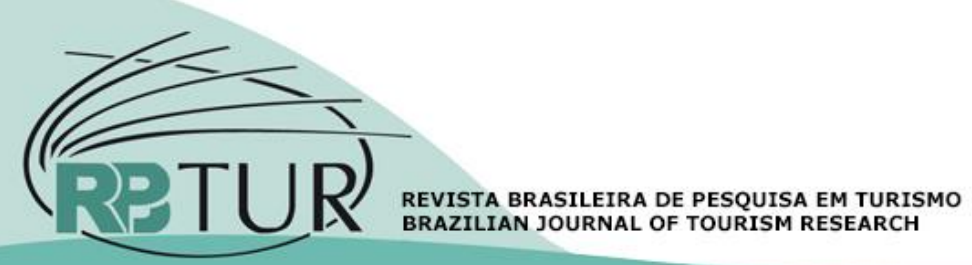

\title{
Artigos
}

\section{Análise da rede social da Instância de Governança do Circuito Turístico Caminho Novo, MG: uma perspectiva} sistêmica e complexa ${ }^{1,2}$

\author{
Analysis of the social network of the Instance of Governance of the \\ Caminho Novo Tourist Circuit, MG: a complex and systemic perspective
}

\section{Análisis de la red social de la Instancia de Gobernanza del Circuito Turístico Caminho Novo, MG: una perspectiva sistémica y compleja}

\author{
Bruno Campos Guilarducci ${ }^{1}$; Aguinaldo Cesar Fratucci ${ }^{1}$ \\ 1 Universidade Federal Fluminense (UFF), Niterói, RJ, Brasil.
}

Palavras-chave:

Turismo;

Sistemas Complexos; Análise de Redes Sociais: Políticas Públicas: Instância de Governança.

\begin{abstract}
Resumo
Essa pesquisa teve como objetivo geral analisar a composição, a organização e o funcionamento do Circuito Turístico Caminho Novo-MG (CTCN), dentro do contexto das políticas públicas de turismo, apoiado na teoria dos sistemas complexos e utilizando como suporte teórico o paradigma da complexidade proposto por Edgar Morin, o modelo do SISTUR de Beni (1998) e sua reconstrução proposta por Moesch e Beni $(2015,2017)$. Como ferramentas metodológicas utilizou-se o método bola de neve aplicado em três etapas, a análise de redes sociais com foco na Teoria dos Laços fracos e Laços fortes de Granovetter $(1973,1983)$ e dos buracos estruturais de Burt (1992), aliadas à análise de conteúdo adaptada de Bardin (2011) e a elaboração de sociogramas das relações mantidas entre os agentes sociais. Como principais re-sultados destacamos a inexistência de uma rede regional capaz de produzir resulta-dos efetivos, o baixo entendimento dos municípios sobre as políticas públicas de turismo, uma forte ingerência municipal e regional atrelada a um cenário de descon-tinuidade da gestão pública e uma postura competitiva com reduzida participação dos agentes sociais para trabalhar em rede.
\end{abstract}

Abstract

The objective of this research was to analyze the composition, organization, and operation

Keywords:

1 Pesquisa realizada com apoio da Coordenação de Aperfeiçoamento de Pessoal de Nível Superior - Brasil (CAPES) Código de Financiamento 001, sendo síntese da dissertação de mestrado apresentada no Programa de PósGraduação Stricto Sensu em Turismo da Universidade Federal Fluminense. Os autores também receberam apoio financeiro da FAPERJ para a versão do artigo para o idioma inglês.

2 Artigo premiado no Prêmio Mestre Destaque ANPTUR 2018 ( $3^{\circ}$ lugar) no XV Seminário da Associação Nacional de Pesquisa e Pós-Graduação em Turismo ANPTUR, realizado entre os dias 19 e 21 de setembro de 2018, na Universidade Anhembi Morumbi - UAM, São Paulo-SP. 
Complex Systems;

Social Network Analysis; Public Policy;

Instance Of Governance.

Palavras clave:

Turismo;

Sistemas Complejos;

Análisis de Redes Sociales;

Políticas Públicas;

Instancia de Gobernanza.

Revisado por pares.

Recebido em: 22/05/2019.

Aprovado em: 02/08/2019.

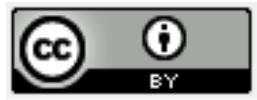

of the Caminho Novo-MG Tourist Circuit (CTCN), within the context of public tourism policies, supported by complex systems theory and using as support (1998) and his reconstruction proposed by Moesch and Beni $(2015,2017)$. As methodological tools, we used the snowball method applied in three steps, the analysis of social networks focusing on the theory of weak and strong ties of Granovetter $(1973,1983)$ and the structural holes of Burt (1992). Also, it was used in the research the content analysis adapted of Bardin (2011) and the elaboration of sociograms of the relationships maintained between social agents. As the main results, we highlight the lack of a regional network capable of producing useful results, the low understanding of the municipalities on public tourism policies, a substantial municipal and regional interference linked to a scenario of discontinuity of public management and a competitive position with reduced participation of social agents to work in a network.

Resumen

Esta investigación tuvo como objetivo general analizar la composición, la organización y el funcionamiento del Circuito Turístico Caminho Novo-MG (CTCN), dentro del contexto de las políticas públicas de turismo, apoyado en la teoría de los sistemas complejos y utilizando como soporte el paradigma de la complejidad propuesto por Edgar Morin, el modelo del SISTUR de Beni (1998) y su reconstrucción propuesta por Moesch y Beni $(2015,2017)$. Como herramientas metodológicas se utilizó el método bola de nieve aplicado en tres etapas, el análisis de redes sociales con foco en la Teoría de los Lazos débiles y los lazos fuertes de Granovetter $(1973,1983)$ y de los agujeros estructurales de Burt (1992), junto al análisis de contenido adaptado de Bardin (2011) y la elaboración de sociogramas de las relaciones mantenidas entre los agentes sociales. Como principales resultados destacamos la inexistencia de una red regional capaz de producir resultados efectivos, el bajo entendimiento de los municipios sobre las políticas públicas de turismo, una fuerte injerencia municipal y regional vinculada a un escenario de discontinuidad de la gestión pública y una postura competitiva con reducida participación de los agentes sociales para trabajar en red.

Guilarducci, B. C.; Fratucci, A. C. (2020). Análise da rede social da Instância de Governança do Cir-cuito Turístico Caminho Novo, MG: uma perspectiva sis-têmica e complexa. Revista Brasileira de Pesquisa em Turismo, São Paulo, 14 (1), p. 140-160, Jan./Apr. http://dx.doi.org/10.7784/rbtur.v14i1.1734

\section{INTRODUÇÃO}

A complexa relação sistêmica do fenômeno socioespacial do turismo se estabelece por meio das interconexões estabelecidas entre os agentes sociais que atuam e produzem esse sistema, geradoras de uma rede complexa gerida por políticas públicas que buscam ordenar e sistematizar a atividade turística dentro dos seus diversos níveis escalares de atuação.

Considerando a escala administrativa federal como responsável por estabelecer os rumos das políticas brasileiras de turismo, tem-se a Política Nacional de Turismo, fundamentada na Lei Geral do Turismo de 2008 e detalhada pelos Planos Nacionais de Turismo (2003-2007, 2007-2010, 2013-2016), propostos pelo Ministério do Turismo (MTUR). Nesse contexto, o tema desse estudo tem como base a política mineira de criação dos circuitos turísticos e o Macro programa de Regionalização do Turismo (PRT).

Na escala estadual e no caso específico desta pesquisa, o estado de Minas Gerais, o alinhamento com o governo federal se dá pelas instâncias de governança regionais, representadas pelos Circuitos Turísticos que constituem a principal ferramenta para desenvolver e ordenar de forma descentralizada o turismo em toda a extensão territorial estadual. Pelo Decreto Estadual no 43.321/2003, Minas Gerais deu um grande passo ao reconhecer e institucionalizar os Circuitos Turísticos como instrumento essencial para desenvolver o processo das políticas de turismo integrado ao PRT, considerando circuito turístico como municípios de uma mesma região com afinidades culturais, sociais e econômicas, unidos em prol da organização do turismo de forma sustentável por meio de uma integração regional (Minas Gerais, 2003a).

No nivel de gestão estadual, a Secretaria de Estado de Turismo de Minas Gerais (SETUR-MG) é a entidade regulamentadora e propositiva que coordena os rumos da política de regionalização no estado. Como forma de legitimar e fortalecer a política pública de Turismo a SETUR-MG, baseada na Resolução SETUR $n^{\circ}$ 007/2003, determinou uma série de parâmetros e exigências para que os Circuitos Turísticos possam receber anualmente o seu certificado de reconhecimento (Minas Gerais, 2003b). 
Com base nesse escopo legal, esta pesquisa busca constituir uma relação entre sistemas complexos e o turismo pelo viés da teoria da complexidade de Edgar Morin (2000; 2002a; 2015), no intuito de estabelecer uma conexão entre os agentes sociais envolvidos nas redes sociais que se formam a partir da implementação das políticas públicas de turismo. Na busca de compreender o fenômeno turístico como um sistema, buscou-se apoio em autores clássicos como Leiper (1979), Boullón (1990) e Beni (1998) que, de forma distinta, abordam o sistema turístico no intuito de explicar a dinâmica estrutural, territorial e multisetorial presente na atividade turística.

Para ampliar a discussão sobre o fenômeno socioespacial do turismo e suas conexões com os sistemas complexos propõem-se ainda, aprofundar a discussão sobre o sistema turístico a partir do ponto de vista dialógico hologramático, observado na concepção de um sistema que se auto organiza e que se autoproduz constantemente. Corroborando nessa concepção, Moesch e Beni (2015) e Beni e Moesch (2017) apresentaram avanços e inovações na reconstrução do modelo de SISTUR anteriormente proposto por Mário Carlos Beni (1998).

Compreendidos como instâncias de governança regional, os Circuitos Turísticos de Minas Gerais constituem uma estratégia de planejamento proposta para administrar e produzir resultados eficazes no ordenamento territorial do turismo daquele estado. A pesquisa ora apresentada demonstrou que a política dos Circuitos Turísticos ainda carece de ferramentas de gestão que consolidem o papel daquelas instâncias de governança como sujeito articulador dos agentes sociais que atuam, de forma direta ou indireta, na complexidade sistêmica que envolve todo o contexto do turismo estadual.

Tomando como base tais considerações aliadas à vivência de um dos autores na condição de presidente da Instância de Governança do Circuito Turístico Caminho Novo (CTCN), no período de 2015-2017, propôsse como hipótese de pesquisa que, mesmo constituída formalmente como principal interlocutor regional, aquela instância ainda apresenta dificuldades para gerir o processo de desenvolvimento turístico em sua região e estabelecer redes regionais entre agentes sociais do turismo de forma sistêmica e complexa.

Esse direcionamento nos permite relacionar os sistemas complexos às políticas públicas, dada a sua abrangência de conexão com agentes sociais, empresas, instituições, o sistema econômico e uma gama variada de situações que se justapõem, se retroalimentam e que possuem comportamentos não lineares. Entendendo assim, que as "políticas públicas também abarcam uma série de questões setoriais que são entrelaçadas, assíncronas e especialmente sobrepostas" (Furtado, 2015, p. 21). Nesse contexto, propõese como fundamental conhecer em profundidade as conexões entre sistemas complexos que se interrelacionam a partir da atuação dos seus agentes sociais, dado que o objetivo de "uma análise de sistemas complexos de políticas públicas é [deva ser] fornecer uma visão e uma compreensão de como o sistema complexo da sociedade pode ser afetado pela aplicação de uma política" (Rand, 2015. p. 46).

O objeto empírico deste estudo, o Circuito Turístico Caminho Novo, na condição de uma Instância de Governança Regional, está inserido dentro do contexto sistêmico complexo que compõe a trama de relações sociais que se desenrola na gestão e formação das políticas públicas de turismo no Brasil, em especial de Minas Gerais. O CTCN contempla o território localizado na Zona da Mata Mineira (sudeste do estado de Minas Gerais, próximo à divisa do estado do Rio de Janeiro), na Microrregião de Juiz de Fora. Seus fundadores foram os municípios de Simão Pereira, Santos Dumont, Santana do Deserto, Matias Barbosa, Juiz de Fora, Ewbank da Câmara e Antônio Carlos. No momento atual (2019), o Circuito está composto pelos municípios de Simão Pereira, Santana do Deserto, Matias Barbosa, Juiz de Fora, Santos Dumont, Mercês e Belmiro Braga.

O presente artigo é uma síntese da pesquisa de dissertação de mestrado de um dos autores e está estruturado em três seções, além desta introdução e das considerações finais. A primeira seção apresenta uma síntese da revisão de literatura abordando a teoria geral de sistemas, o SISTUR, os sistemas complexos e as relações entre as políticas públicas de turismo, sistemas complexos e redes sociais. Na segunda seção apresenta-se a metodologia de pesquisa utilizada, estruturada a partir da ferramenta da análise de redes sociais. Na terceira seção são apresentados e discutidos os resultados encontrados com a pesquisa. 


\section{TURISMO, SISTEMAS COMPLEXOS E POLÍTICAS PÚBLICAS}

O turismo entendido como um fenômeno socioespacial complexo envolve um conjunto de relações de cunho territorial, social, econômico, espacial e temporal, em um contexto com características multifacetadas e uma dinâmica de agentes sociais conectados em redes interativas, como descrito por Knupp (2014), Fratucci (2008) e Baggio $(2008,2006)$, dentre outros. Dada tal complexidade, seu entendimento deve buscar apoio em conceitos e teorias que sejam capazes de explicar a multiplicidade de relações, interações e interconexões que ocorrem dentro do sistema do turismo enquanto um campo científico em constante construção.

Para tanto, esta pesquisa apoia-se na Teoria Geral dos Sistemas de Bertalanffy (2009), por entender que essa teoria mudou o rumo da ciência ao introduzir o pensamento sistêmico. Como base filosófica optou-se pelo Paradigma da Complexidade do filosofo Edgar Morin (2000; 2002a; 2015), com o intuito de demonstrar o turismo como um fenômeno complexo com capacidade de se "auto-eco-organizar" (Morin, 2015), e de influenciar seu ambiente pelo ecossistema em que está inserido.

Para que um sistema possa ser estruturado ele deve estar em um meio ambiente, possuir unidades, manter relações entre suas unidades, ter seus atributos próprios e, sobretudo, possuir inputs (entradas) e outputs (saídas) (Panosso, 2008). Operando nessa linha de raciocínio, pode-se dizer que "todo organismo vivo é essencialmente um sistema aberto. Mantém-se em um contínuo fluxo de entrada e de saída, conserva-se mediante a construção e a decomposição de componentes" (Bertalanffy, 2009. p. 65).

Todo sistema aumenta seu grau de complexidade "quando sua existência e a manutenção de sua diversidade são inseparáveis de inter-relações com o ambiente, por meio das quais o sistema tira do externo matéria/energia e, em grau superior de complexidade" (Morin, 2000. p. 292). Do ponto de vista teórico e empírico, o conceito de sistema aberto "abre a porta a uma teoria da evolução, que só pode provir das interações entre sistema e ecossistema, e que, em seus saltos organizacionais mais admiráveis, pode ser concebida como a superação do sistema por um metasistema" (Morin, 2015. p. 22).

Essa conexão estabelecida entre sistemas, subsistemas, ecossistemas e metasistemas, gera uma interdependência de retroalimentação, de auto-eco-organização entre os diversos níveis escalares em que os sistemas se encontram e nas suas relações diretas com seu ambiente. Nesses moldes, o ser humano está naturalmente inserido em todas as redes de conexões que se fazem presentes nos sistemas sociais, ecológicos, moleculares e tecnológicos, onde há comumente interações que se sobrepõem e se justapõem.

Trazendo essa contextualização sobre sistemas e redes para dentro do campo de estudos do turismo, entendemos que a atividade turística está intrinsecamente relacionada ao sistemismo. Temos em vista que para se desenvolver, o turismo necessita de uma ampla rede relacional que opera dentro de sistemas interdependentes, que se ligam diretamente a vários outros sistemas e subsistemas. Por consequência, trata-se de um fenômeno socioespacial interdependente e interconectado, que não se reduz às suas partes, com sua compreensão exigindo uma visão mais ampla, que remete à ideia de interação sistêmica.

\subsection{A Teoria Geral dos Sistemas aplicada ao estudo do turismo}

A Teoria Geral dos Sistemas (TGS) contribuiu com uma nova forma de compreensão dos processos dinâmicos e interativos que são encontrados nos mais diversos ramos da ciência. Essa percepção rompeu com a obscurecência analítica e cartesiana e despertou para uma visão sistêmica, de modo que as relações e os conjuntos assumem uma importância destacada nas análises de interatividade e interdependência, em que compreender o todo é muito mais importante do que simplesmente se atentar meramente à análise isolada de suas partes.

De tal forma, na busca por um entendimento epistemológico e conceitual sobre como opera o sistema turístico, diversos autores como Leiper (1979), Boullón (1990), Molina (1991), Gunn (1996), Sessa (1983), Beni (1998), Petrocchi (2002), Jiménez (2005) dentre outros, buscaram embasamento na teoria geral dos sistemas para construir seus modelos com o intuito de explicar a dinâmica sistêmica encontrada no contexto do fenômeno socioespacial e sociocultural do turismo. 
As abordagens propostas por Leiper (1979), Boullón (1990) e Beni (1998) sobre modelos de sistemas turísticos nos possibilitam uma reflexão que nos remete ao entendimento de o turismo operar como um sistema aberto, permanentemente conectado e em interação com seu ambiente. Ele deve ser pensado, estudado, desenvolvido e conceituado a partir das conexões interativas dos elementos que o compõem e não somente pela análise isolada de suas partes. Faz-se necessária uma abordagem que considere o fenômeno turístico como um sistema que se retroalimenta, se auto organiza e se relaciona com outros sistemas, a partir de um meta sistema. Assim, torna-se fundamental considerar as relações dialógicas, concorrentes, antagônicas, complementares e retro agentes (Morin, 2000; 2002b; 2011) que se estabelecem em todos os momentos e etapas do SISTUR.

\subsection{A reconstrução do SISTUR a partir do Paradigma da Complexidade}

No atual contexto dos estudos do turismo com base na teoria geral dos sistemas, os avanços científicos e epistemológicos devem prosseguir com mais profundidade dentro de uma perspectiva complexa, interativa, na visão de um sistema vivo que se retroalimenta e que se auto organiza. Um avanço nesse sentido pode ocorrer a partir da adoção do paradigma da complexidade proposto pelo filósofo Edgar Morin (2000; 2002a; 2015), para compreender o fenômeno turístico. Tal proposta pressupõe inovações e impactos sobre a produção do conhecimento turístico, perpassando seu aprofundando e sua compreensão fundamentada dentro de uma visão sistêmica e complexa.

A primeira etapa da complexidade proposta na construção da epistemologia do turismo, segundo o pensamento complexo de Morin (2000), é o rompimento com a simplicidade na forma de pensar o objeto do turismo, mesmo que esses conhecimentos simples nos ajudem a conhecer algumas propriedades do conjunto. No sistema turístico, como em toda a organização viva, os subsistemas não estão dispostos ao acaso, pelo contrário, eles estão "organizados em função de um tecido de sustentação que serve de sustentação [sic] das diversas estruturas do sistema, de uma unidade sintética em que cada parte contribui ao conjunto" (Moesch, 2013. p. 16).

Do ponto de vista sistêmico e de sua dinâmica, Moesch e Beni (2015) e Beni e Moesch (2017) identificaram limitações no modelo original do SISTUR proposto por Beni (1998), para sua aplicação nos estudos sobre as dimensões epistemológicas e teóricas do fenômeno turístico contemporâneo. Diante disso, eles apontam para o "paradigma holístico da interdisciplinaridade e da transdisciplinaridade, expressa por essa discussão, como necessidade para uma ação na construção da epistemologia do turismo" (Moesch \& Beni, 2015. p. 16). A insuficiência do modelo do SISTUR (BENI, 1998) se dava pela análise dos seus conjuntos e de seus subsistemas. A partir do entendimento de suas partes buscava-se explicar toda a interação do sistema, o que seria falho "pois a simples soma das partes não revela a complexidade de suas conexões e a dinâmica das relações" (Moesch \& Beni, 2015, p. 16).

Para tanto, os autores se apoiaram na teoria da complexidade de Edgar Morin (2000) para apresentar um novo modelo para a reconstrução do SISTUR, que o compreende como "sistema vivo, que se auto-organiza, e realiza sua autoprodução, ao mesmo tempo em que realiza a auto-eco-organização e a sua auto-ecoprodução, pois ele está envolvido em um ambiente externo que se encontra, ele mesmo, integrado a um sistema eco-organizador, o ecossistema" (Moesch \& Beni, 2015. p. 09).

O SISTUR, reconstruído dentro desses parâmetros pode ser observado como um sistema interativo, que não se reduz a si mesmo. Ele está constantemente se auto organizando, sendo influenciado pelo seu ambiente externo (ecossistema) e pelo seu comportamento interno (rede de produção), ao mesmo tempo se conectando e sendo influenciado pelos agentes que compõem o cluster turístico, comumente girando dentro de um espaço/tempo presente em um território. (Guilarducci \& Fratucci. 2016).

Tal entendimento do SISTUR, passa pela sua compreensão como um sistema dinâmico, interativo que possui um movimento circular, contínuo e aberto que mantém relações de troca energética, passando seu entendimento como um sistema aberto e "dentro dessa concepção do sistema turístico aberto e orgânico, na forma de um holograma, a energia que propicia a sua dinâmica é humana” (Moesch, 2013, p. 20). 
Toda essa interação de conexões de auto-organização produz conectividades que, somadas aos processos sociais que inevitavelmente ocorrem no turismo, geram uma rede social e territorial complexa entre agentes sociais que contribui para a construção do saber turístico. Isso se reflete nas ações de ordenamento e gestão do território e nas interrelações entre os agentes sociais com as políticas públicas que produzem uma série de eventos de magnitude social, econômica e cultural, que devem ser observados pela ótica da complexidade, dado que possuem subsídios capazes de fornecer um melhor entendimento sobre o fenômeno turístico (Guilarducci \& Fratucci. 2016).

O modelo apresentado pelos pesquisadores Beni e Moesch (2015) e Beni e Moesch (2017) do ponto de vista do turismo como um sistema complexo apresentou inovações e trouxe uma nova visão para os estudos do setor. Por outro lado, apoiado em uma observação mais atenta e minuciosa no modelo apresentado é ainda possível identificar algumas lacunas quando analisado pelo viés da complexidade. Tal proposta ainda carece de elementos que figurem a interconexão e auto-organização presente em sistemas complexos que sejam capazes de demonstrar de maneira mais clara e objetiva a conectividade entre os elementos presentes e sua conexão com o todo sistêmico.

Em nossa concepção, para a construção da proposta de um modelo de Sistema Turístico que seja capaz de atender aos aspectos intrínsecos aos sistemas complexos com sua auto-eco-organização, se faz necessário buscar apoio no modelo toroidal proposto e patenteado pelo físico Nassim Haramein (2015a, 2015b, 2016a, 2016b, 2016c, 2016d). A partir dele entendemos ser possível adaptar e construir uma proposta para um novo modelo de Sistema Turístico que agregue e unifique o fenômeno turístico, deixando-o conectado com sua capacidade de atingir todos os seus aspectos mais profundos, complexos e de interconectividades. Entretanto, não é aqui o momento de delinear com mais precisão todos esses apontamentos, dado que urge a necessidade de um estudo mais detalhado e aprofundado dentro dos liames dos sistemas complexos e do modelo toroidal.

\subsection{Breves reflexões teóricas sobre sistemas complexos}

Sobre a ótica da complexidade, sistemas coexistem com possibilidades de interação e sua aplicação se dá em diversos níveis escalares, atuando dentro de uma lógica complexa, onde há fatores não previsíveis e em constante alteração. Essa concepção de multinteração, multidisciplinar e dinâmica é corroborada por Fuentes quando afirma que "a ciência da complexidade não é um ramo disciplinar da ciência, é uma inter/transdisciplinar exploração da natureza, em quase todas as escalas e ambientes" (Fuentes, 2015, p. $65)$.

Tais interrelações e conectividades disciplinares se estabelecem em diversos tipos de escalas e se ligam a outros sistemas não previsíveis de forma não linear, o que produz uma constante adaptação do próprio sistema e de seu padrão. A imprevisibilidade, o grande número de interações, a permanente mudança e sua não linearidade são peculiaridades intrínsecas para compreensão dos sistemas complexos. Nesse sentido, 'sistema complexo' pode ser definido como um "sistema em que grandes redes de componentes sem nenhum controle central e com regras simples de operação dão origem a comportamento complexos coletivos" (Mitchell, 2009, p. 13).

Os sistemas dentro de uma lógica social reagem diante a demanda que se entrelaça entre acaso, ordem e desordem num movimento dialógico, recursivo e complementar, que comumente se auto organiza pelas suas próprias forças antagônicas. Toda essa instabilidade sem equilíbrio contribui para a retroação organizacional produzida no seio das próprias inter-relações sociais, formando um tecido social sistêmico e complexo, que se auto organiza. Assim, a "complexidade não se reduz à incerteza, é a incerteza no seio de sistemas ricamente organizados. Ela diz respeito a sistemas semialeatórios cuja ordem é inseparável dos acasos que os concernem" (Morin, 2015, p. 35).

Nessa linha de pensamento complexo e sistêmico, o turismo insere-se como um fenômeno socioespacial e sociocultural que envolve uma série de ações de magnitude complexa para que possa acontecer de forma plena. 
A partir dessa perspectiva, os agentes sociais que atuam nas políticas públicas e no fenômeno turístico, estabelecem conexões relacionais dentro de um sistema social, em uma estrutura reticular complexa. Nesse aspecto, a análise de redes sociais apresenta-se como uma ferramenta metodológica possível para entender essa trama interativa entre indivíduos e instituições e vice-versa, considerando o fluxo contínuo de auto-organização e não linearidade presentes nas relações em rede.

\subsection{Sistemas complexos, redes sociais e políticas públicas de turismo}

O reconhecimento de que as "políticas públicas também abarcam uma série de questões setoriais que são entrelaçadas, assíncronas e especialmente sobrepostas" (Furtado, 2015, p. 21) fica reforçado quando se considera que os pontos de conexão entre elementos dentro do contexto das políticas públicas, constituem-se em sistemas complexos. 0 primeiro ponto a ser considerado é a "idéia forte de interação entre as partes, considerando as escalas e dando relevância espacial e temporal. Essas interações, por sua vez, levam a um sistema que não é redutível as suas partes" (Furtado, 2015, p. 22).

Além desse ponto, deve-se ponderar que a "interação entre as partes pode levar à auto-organização do sistema, sem a necessidade de controle central, implicando que as interações locais podem gerar comportamentos que emergem de baixo para cima" (Furtado, 2015, p. 22). 0 terceiro ponto de conexão entre sistemas complexos e políticas públicas pode ser caracterizado pelo efeito no tempo, onde a aplicação de uma ação em um determinado momento tem repercussão em situações futuras. Essas três considerações nos permitem afirmar que "é por isso que sistemas complexos são caracterizados como sistemas que aprendem, se adaptam e evoluem" (Furtado, 2015, p. 22).

Assim sendo, as políticas públicas precisam considerar a dinâmica dos sistemas, pois há uma constante retroalimentação sistêmica que gera fluxos e reações não previsíveis. Para tanto, é importante considerar que após a implementação de determinadas políticas, alguns comportamentos sociais podem ser imprevisíveis, tendo em vista a subjetividade de cada agente social e, sobretudo, os interesses dos agentes e das organizações envolvidas.

Alguns autores, como Gentile et al (2015) e Rand (2015), consideram as pessoas como seres complexos e imprevisíveis que se refletem nos sistemas sociais que "compreendem indivíduos autônomos que não se comportam de forma perfeitamente racional e que têm diferentes modelos mentais explicativos de como a sociedade funciona" (Gentile et al, 2015, p. 85). Dessa maneira, o "objetivo da política pública é muitas vezes alterar ou manter o comportamento de um grande grupo de indivíduos ou organizações para o alcance de um resultado socialmente desejável" (Rand, 2015, p. 43).

Sob esse aspecto percebe-se que, de um modo geral, as políticas públicas de turismo brasileiras têm sido pensadas e desenvolvidas desconsiderando os aspectos complexos inerentes aos agentes sociais produtores do fenômeno (Fratucci, 2008), o que produz ações equivocadas que acabam não atingindo os objetivos necessários de transformações sociais pretendidos. A mudança tática dessas políticas deveria levar em consideração a conjuntura dos sistemas complexos, sobretudo porque a complexidade sistêmica exige a aplicação de metodologias e métodos que possibilitem sua análise de forma mais abrangente.

Vistos de tal maneira, os elementos metodológicos utilizados pela concepção dos sistemas complexos podem ser assumidos como instrumentos fundamentais para aplicação no campo das políticas públicas. 0 objetivo de "uma análise de sistemas complexos de políticas públicas é fornecer uma visão e uma compreensão de como o sistema complexo da sociedade pode ser afetado pela aplicação de uma política" (Rand, 2015, p. 46). Dessa forma, a análise sistêmica complexa pode oferecer ferramentas capazes de dar suporte ao entendimento e à implementação de políticas públicas em diversos setores, dentre eles o de turismo.

A partir dessa perspectiva, os agentes sociais que atuam nas políticas públicas e no fenômeno turístico, estabelecem conexões relacionais dentro de um sistema social, em uma estrutura reticular complexa. Isso influencia toda a teia de inter-relações intrínseca a qualquer fenômeno social, pois onde há pessoas, instituições e governo, existem conexões em formato de redes relacionais. 
A análise de redes sociais apresenta-se como uma das ferramentas possíveis para a compreensão de sistemas complexos, especialmente aqueles onde ocorrem conexões entre indivíduos, grupos sociais, empresas e governos. Nesse sentido, o "objetivo da análise das redes sociais e da ciência de redes é entender sistemas complexos ao descrever o sistema de interações que ocorrem dentro do sistema" (Rand, 2015, p. 51). Dentro desses parâmetros, o desafio é compreender a interação entre os agentes sociais inseridos em um sistema complexo onde se estabelecem relações entre os indivíduos e as instituições.

A concepção de redes e agentes sociais interconectados é fundamental para que o fenômeno turístico possa ser apreendido e compreendido, tendo em vista a dependência direta que ele tem de outros setores e sistemas. As redes relacionais estabelecidas dentro do fenômeno socioespacial do turismo estão vinculadas aos agentes sociais envolvidos no sistema e nos subsistemas que compõem uma estrutura ecossistêmica, a qual dá suporte para o funcionamento de uma trama de interconexões encontradas no ambiente ou meta sistema turístico.

Assim, o sistema turístico está interligado através de redes regionais estabelecidas pelas políticas públicas do setor que seguem uma estrutura verticalizada, tendo suas deliberações oriundas da esfera federal, passando pela estadual e culminando na administração municipal. Mesmo dentro desse modelo verticalizado, a gestão pública produz uma rede complexa de interações circulares, complementares e recursivas, onde cada agente assume um nível de centralidade dentro da estrutura.

No campo das políticas públicas, conhecer em profundidade as conexões entre sistemas complexos que se inter-relacionam através da atuação dos seus agentes sociais, pode revelar-se útil para o desenvolvimento de políticas adequadas com um maior índice de assertividade. A análise de redes sociais pode ser considerada uma ferramenta que contribui de forma significativa para o desenvolvimento e o monitoramento de políticas públicas, pois permite que se discutam os "efeitos da complexa interdependência presente na produção de políticas sobre a ação social, considerando não apenas as ligações em torno dos atores, mas também a estrutura dos vínculos e os padrões gerais em que esses estão inseridos" (Marques, 2006, p. 20).

Por esse viés, a complexidade inerente aos sistemas e às políticas públicas revela-se em sua própria rede de atuação e na sua conexão com outras redes que, por sua vez, se conectam por relações 'orientadas' e 'não orientadas' com outros agentes e com outras redes e até mesmo, com outros sistemas complexos.

Dentro desse contexto teórico conceitual, o foco de investigação dessa pesquisa passa diretamente pela compreensão das redes de políticas públicas que se formam especificamente no Estado de Minas Gerais, a partir da política de regionalização do turismo, desenvolvida no Brasil e implementada naquele estado com a criação dos Circuitos Turísticos Mineiros. O objeto empírico desse estudo, o Circuito Turístico Caminho Novo, se encaixa dentro dessa rede de política pública, envolvendo fluxos e relações de conexão entre indivíduos, instituições, grupos sociais e suas interconexões com as estruturas públicas reguladoras desses agentes sociais.

\section{PERCURSO METODOLÓGICO DA PESQUISA}

Este estudo está estruturado como uma pesquisa qualitativa exploratória, realizada no período de setembro de 2015 a agosto de 2017. O objetivo desse trabalho foi analisar a composição, a organização e o funcionamento da rede social da Instância de Governança do Circuito Turístico Caminho Novo (CTCN), tendo em conta os pressupostos estabelecidos pelas políticas públicas de turismo no Brasil que indicam tais instâncias como as responsáveis diretas para articular, fortalecer e gerir a rede de agentes sociais de cada região turística.

$\mathrm{Na}$ busca para entender essa complexa trama de relações, a pesquisa foi norteada pela teoria da complexidade de Edgar Morin (2000; 2002a; 2002b; 2002c) sustentada metodologicamente pela ferramenta de análise de redes sociais, que permitiram o estudo das inter-relações que envolvem sincronicamente os processos sociais e políticos relacionados ao fenômeno socioespacial produzido pela atividade turística na região, tendo como foco principal o estudo dos laços relacionais que o CTCN estabelece entre os agentes 
sociais atuantes nas esferas local, regional, estadual e federal, principalmente na sua dimensão políticoterritorial.

As relações e as conexões dos agentes sociais e o papel que cada um assume dentro da sociedade, estabelecem interações que contribuem para a formação da estrutura social, culminando em redes sociais dinâmicas, com alto grau de complexidade. Toda essa trama relacional com níveis distintos de complexidade tem gerado diversificados estudos e pesquisas dentro das ciências sociais, direcionados para entender os processos de conexão em nível social e institucional.

A análise de redes sociais (social network analysis/SNA) proposta por Warren (2007) é uma ferramenta metodológica de origem "multidisciplinar (psicologia, sociologia, antropologia, matemática, estatística) cuja principal vantagem é a possibilidade de formalização gráfica e quantitativa de conceitos abstraídos a partir de propriedades e processos característicos da realidade social” (Souza \& Quandit, 2008, p. 31), constituindo-se em "uma abordagem focada na análise da estrutura dos fenômenos, principalmente nas interrelações entre os atores" (Recuero, 2015, p. 45).

A partir da visão de representação uma rede constitui-se em um conjunto de pontos ou nós (nodes) ligados por elos (ties), considerando que esses 'nós' constituem um conjunto de atores (set). Graficamente os 'elos não-direcionados' (non directed ties) são representados por linhas retas ou curvas (lines), ao passo que 'elos direcionados' (directed ties) são referenciados por linhas retas ou curvas terminadas por setas (arcs) (Souza \& Quandt, 2008).

Do ponto de vista teórico-empírico, existem diferentes possibilidades explicativas sobre a análise de redes sociais e a teoria dos laços fortes e dos laços fracos de Granovetter $(1973 ; 1983)$ se insere nesse panorama. Segundo Lemieux (2012), refletindo sobre a teoria de Granovetter, os laços fortes ou estreitos nos unem aos indivíduos mais próximos de nós, como por exemplo, aos parentes mais próximos como (pais, primos, amigos, cônjuges) e os laços fracos ou frouxos nos ligam a parentes mais afastados, colegas de turma e a vizinhança com a qual não temos laços de amizade (Lemieux, 2012).

Outra forma de aplicação teórica empírica na análise de redes sociais é a teoria dos buracos estruturais, elaborada por Burt (1992), que tem como ponto central o tertius gaudens, ou seja, quando um ator social obtém vantagem do conflito entre outros dois. Ele possui uma posição vantajosa pelo fato de intermediar uma relação entre dois indivíduos que não mantêm relação entre si. O tertius gaudens pode se valer de duas estratégias de acordo com o tipo de relação que mantiver com cada uma das partes envolvidas nesse buraco estrutural que se forma entre esses três atores.

No campo das políticas públicas a análise de redes sociais pode ser considerada uma ferramenta que contribui de forma significativa para o desenvolvimento e o monitoramento dessas políticas pois permite que se discutam os "efeitos da complexa interdependência presente na produção de políticas sobre a ação social, considerando não apenas as ligações em torno dos atores, mas também a estrutura dos vínculos e os padrões gerais em que esses estão inseridos" (Marques, 2006, p. 20).

Para produzir a análise sobre a rede social do Circuito Turístico Caminho Novo foi utilizado o método bola de neve, aplicado em três rodadas que contribuíram para a produção de uma matriz de pesquisa, utilizada como forma de estabelecer os parâmetros para analisar e sistematizar os dados da pesquisa. Além disso, foi utilizado o software yED Graph@ a partir da ferramenta centralidade de intercessão entre nós (Node Betweenness Centrality) para produzir os sociogramas da rede formal, teórica e apontada pelos agentes sociais entrevistados e da rede possível, formada pelos agentes indicados nas entrevistas acrescidos dos seus parceiros, associados e serviços não apontadas pelos agentes sociais entrevistados.

Com o apoio do método bola de neve e da matriz de pesquisa visando o aprofundamento da pesquisa, foi aplicado um questionário por correio eletrônico à equipe técnica da Secretaria de Estado de Turismo de Minas Gerais (SETUR-MG) e aos membros da Federação dos Circuitos Turísticos (FECITUR). Concomitante foram realizadas entrevistas estruturadas com os principais agentes envolvidos com turismo na região, apontados na segunda fase do método bola de neve, que são CTCN, ABRASEL/ZM, SDETTUR, JFRC\&VB, além de todas as secretarias municipais de turismo que compõem o CTCN. Apesar dos órgãos municipais 
serem membros do CTCN, não foi obtida nenhuma resposta deles às solicitações de entrevistas feitas pelos pesquisadores o que, de certa maneira comprova a hipótese dessa pesquisa que aponta para a fragilidade das estruturas político administrativas daqueles municípios.

Nesse contexto, a análise dos sociogramas, dos questionários e das entrevistas foram norteadas pelas seguintes variáveis operacionais: (a) capacidade dos agentes sociais se articularem em rede; (b) grau de proximidade de relação entre os agentes sociais; (c) nível de capacidade gerencial de uma região turística; (d) formação de redes regionais entre agentes sociais.

\section{A REDE SOCIAL DO CTCN: REDES OBSERVADA, APONTADA E POSSÍVEL}

A análise se iniciou com a produção do sociograma da rede existente ou não, na instância de governança do CTCN. Esta 'rede observada', teórica, foi construída com base na observação participante de um dos autores, diretamente envolvido no contexto das políticas públicas do estado de Minas Gerais, em especial na região de estudo. Essa escolha acabou por levar a uma utilização inicial das entidades que compõem o COMTUR-JF, visto o mesmo congregar em sua composição as instituições mais fortes e representativas do turismo dentro do contexto regional, tendo em vista o município de Juiz de Fora ser o destino indutor da região e apresentar uma estrutura urbana e econômica mais complexa que os demais municípios da região. Em seguida, realizou-se uma triagem das instituições identificadas para selecionar os principais agentes envolvidos com o turismo na cidade/região. Nessa decisão foi relevante ao fato de um dos autores ser o presidente do CTCN naquele momento da pesquisa (2016), posição que Ihe dava uma visão bem atualizada dos agentes sociais efetivamente envolvidos com a instância de governança e com o turismo regional.

O mapa da rede observada nessa primeira etapa foi elaborado a partir das relações estabelecidas entre os principais atores ligados ao turismo na região, com o objetivo de identificar qual(is) ator(es) possuíam maior centralidade dentro daquela rede. Nesse sentido, a análise do sociograma na rede formada por essa instância de governança (figura 01) revela um conjunto de ligações e interconexões existentes entre seus grupos e nós. A produção deste sociograma gerou um total de 319 nós (nodes) e 514 laços (edges) e uma autocitação (auto loop) de interconexões estabelecidas entre os agentes sociais da rede. Dentre essas conexões foram observados um total de 20 agentes que exercem atuação de laços fracos, onde cumprem o papel de preencher os buracos estruturais da rede interconectando um ou mais nós ou grupos.

A partir desse resultado, a ferramenta 'centralidade de intercessão' (node beteweenness centrality) estabelece seus parâmetros de cálculo, atribuindo um valor considerando o caminho mais curto para todos os vértices e as conexões entre eles. 0 cálculo ainda considera as relações direcionadas e não direcionadas e, para todos os possíveis caminhos pequenos é estabelecido o valor de 1 e para os caminhos mais curto é empregado o valor de 0 (Social Network Analysis, 2011). Ao considerar isso, quanto mais conexões próximas e interconexões forem estabelecidas por um nó, mais próximo de 1 (um) será seu índice, indicando que maiores serão suas interações e seu poder de influenciar os outros nós na rede. Ele assume uma postura de centralidade na condição de não possuir restrições de acesso a outros grupos igualmente influente ou não. 
Figura 01 - Sociograma da Rede Observada do Circuito Turístico Caminho Novo

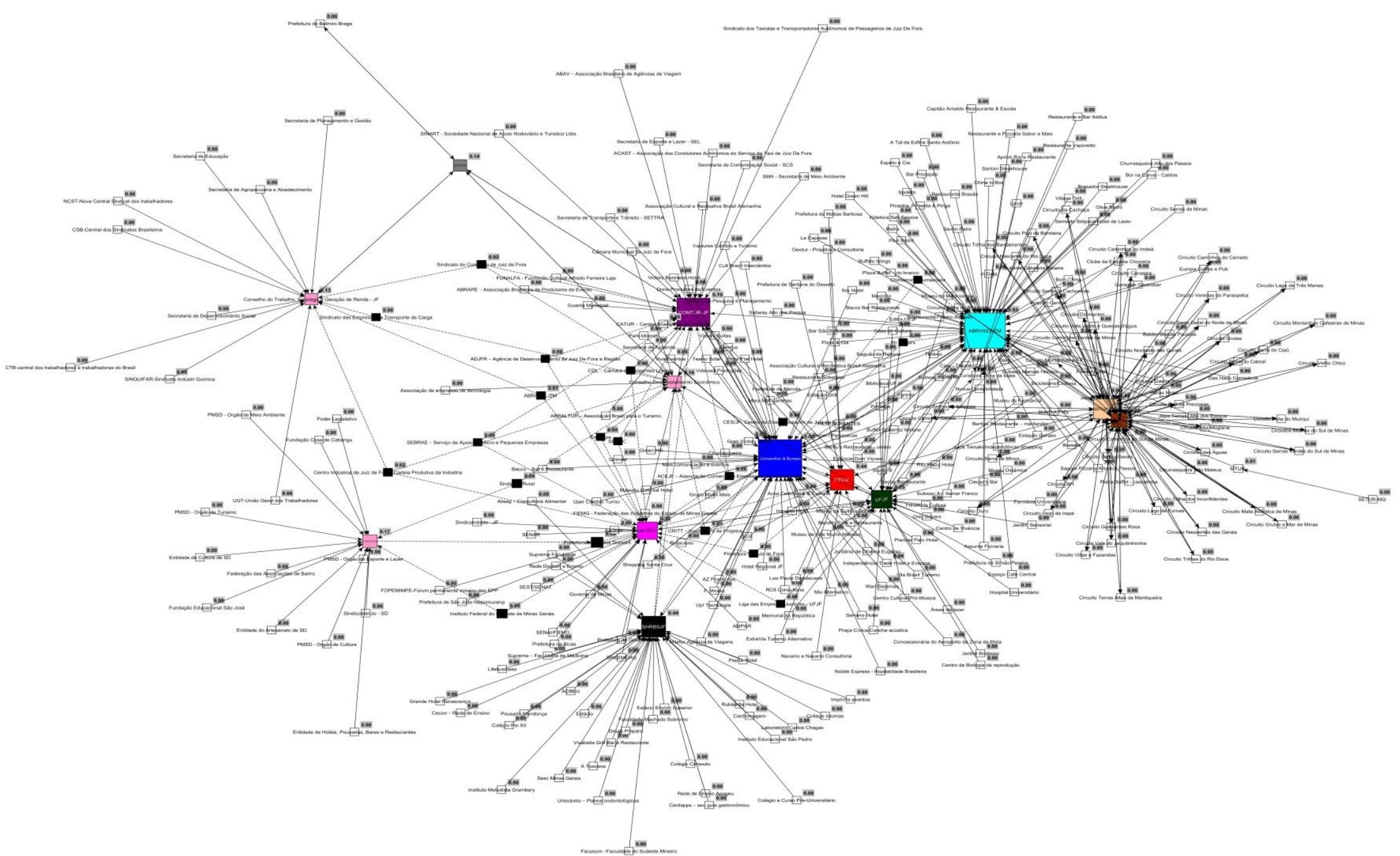

Fonte: Elaboração própria (2017) 
A Tabela 01 apresenta os índices encontrados para cada instituição da rede observada do CTCN, em ordem decrescente, a partir dos quais pode-se dimensionar a intensidade de ligações e a centralidade estabelecida por cada agente na rede observada.

Tabela 01 - Índice das instituições da rede observada

\begin{tabular}{lc}
\hline \multicolumn{1}{c}{ Instituição } & Índice \\
\hline Juiz de Fora e Região Convention \& Visitors Bureau (JFRC\&VB) & 1.0 \\
Associação Brasileira de Bares e Restaurantes/zona d mata mineira (ABRASEL/ZM) & 0.93 \\
Conselho Municipal de Turismo de Juiz de Fora (COMTUR-JF) & 0.70 \\
Circuito Turístico Caminho Novo (CTCN) & 0.44 \\
Sindicato de Hotéis, Restaurantes, Bares e Similares de Juiz de Fora (SHRBSJF) & 0.44 \\
Secretaria de Estado de Turismo de Minas Gerais (SETUR/MG) & 0.42 \\
Universidade Federal de Juiz de Fora (UFJF) & 0.35 \\
Grupo de Trabalho Desenvolvimento e Inovação na Mata Mineira & 0.33 \\
(GDI-MATA) & 0.21 \\
Federação dos Circuitos Turísticos de Minas Gerais (FECITUR) & 0.17 \\
Conselho Municipal de Turismo de Santos Dumont (COMTUR-SD) & 0.16 \\
Conselho de Desenvolvimento Econômico (CDE-JF) & 0.14 \\
Secretaria de Desenvolvimento Econômico, Trabalho e Turismo de Juiz de Fora (SDETTUR) & 0.13 \\
Conselho do Trabalho, Emprego e Geração de Renda de Juiz de Fora (CMGER-JF) & 0.05 \\
Instituto Federal do Sudeste de Minas (IF-SUDESTE) & 0.04 \\
Sindicato Rural de Juiz de Fora & 0.01 \\
Centro Regional de Inovação e Transferência de Tecnologia da UFJF (CRITT) & 0.00 \\
Demais &
\end{tabular}

Fonte: Elaboração própria (2017)

A visualização desta 'rede observada' apresenta como panorama geral a existência de um número elevado de entidades que exercem centralidade e que podem exercer influência direta e indireta nas complexas relações formatadas em uma rede de relações sociais e institucionais. O sociograma indica que essa centralidade se concentra em entidades ligadas ou pertencentes ao município de Juiz de Fora. Algumas são de caráter local (COMTUR JF) e outras, apesar de terem abrangência regional (Convention Bureau, ABRAZELZM etc.), têm sede na cidade de Juiz de Fora, onde possuem maior atuação. Quando se visualiza os índices pelo prisma regional embasado nos liames das políticas públicas de turismo, o CTCN aparece na quarta posição, com índice de 0.44 , compartilhada com a SHRBSJF, o que demonstra que a instância de governança regional está aquém da sua posição ideal de agente centralizador, promovedor do turismo e responsável pela governança regional das políticas do setor. Este resultado reforça a polaridade do município de Juiz de Fora indicando um desequilibro nos processos de desenvolvimento do turismo na região, ainda concentrado no seu destino indutor.

\subsection{Análise do sociograma da rede apontada}

A produção do sociograma da rede apontada pelos agentes sociais, partiu das informações oriundas das entrevistas estruturadas aplicadas às entidades e instituições ligadas ao COMTUR-JF e às secretarias de turismo dos municípios associados ao CTCN. No questionário aplicado foi solicitado que fossem apontadas pelos entrevistados quais entidades possuíam maior importância para a gestão do turismo em nível regional. Junto a isso, foi solicitado também, que atribuíssem valores para cada uma das entidades apontadas, considerando uma escala de 0 a 10, para indicar seu nível de importância para o turismo da região. Os resultados apontaram que as entidades/instituições com maior representatividade para a gestão do turismo regional são SHRBSJF, JFRC\&VB, ABRASEL/ZM, SDETTUR, Prefeitura de Juiz de Fora (PJF), CTCN, UFJF, SEBRAE e SENAC.

O sociograma produzido com as informações obtidas indica uma rede com ligações reduzidas e compostas por poucos agentes sociais, destacando a presença de laços fortes, fechados entre si, compartilhados dentro de um pequeno grupo que fortalece suas conexões internas e se fecha às conexões externas. Verifica-se também a inexistência de buracos estruturais e de relações com laços fracos, pois não são visualizados agentes que estabeleçam conexões fora do grupo restrito mantido pela rede. 
Ao se considerar o caráter simplista do padrão relacional mantido nessa rede, sua interlocução com a complexidade fica empobrecida dado que se afasta dos preceitos básicos dos sistemas complexos, tendo em vista que o sociograma aponta para 09 nós, 18 laços e quatro autocitações (auto loop). São, nesse aspecto, os padrões de comportamento e de interação que guardam o sistema de relações e posicionam os atores de acordo com sua funcionalidade (Aguirre, 2011).

Figura 02 - Sociograma da Rede Apontada do Circuito Turístico Caminho Novo

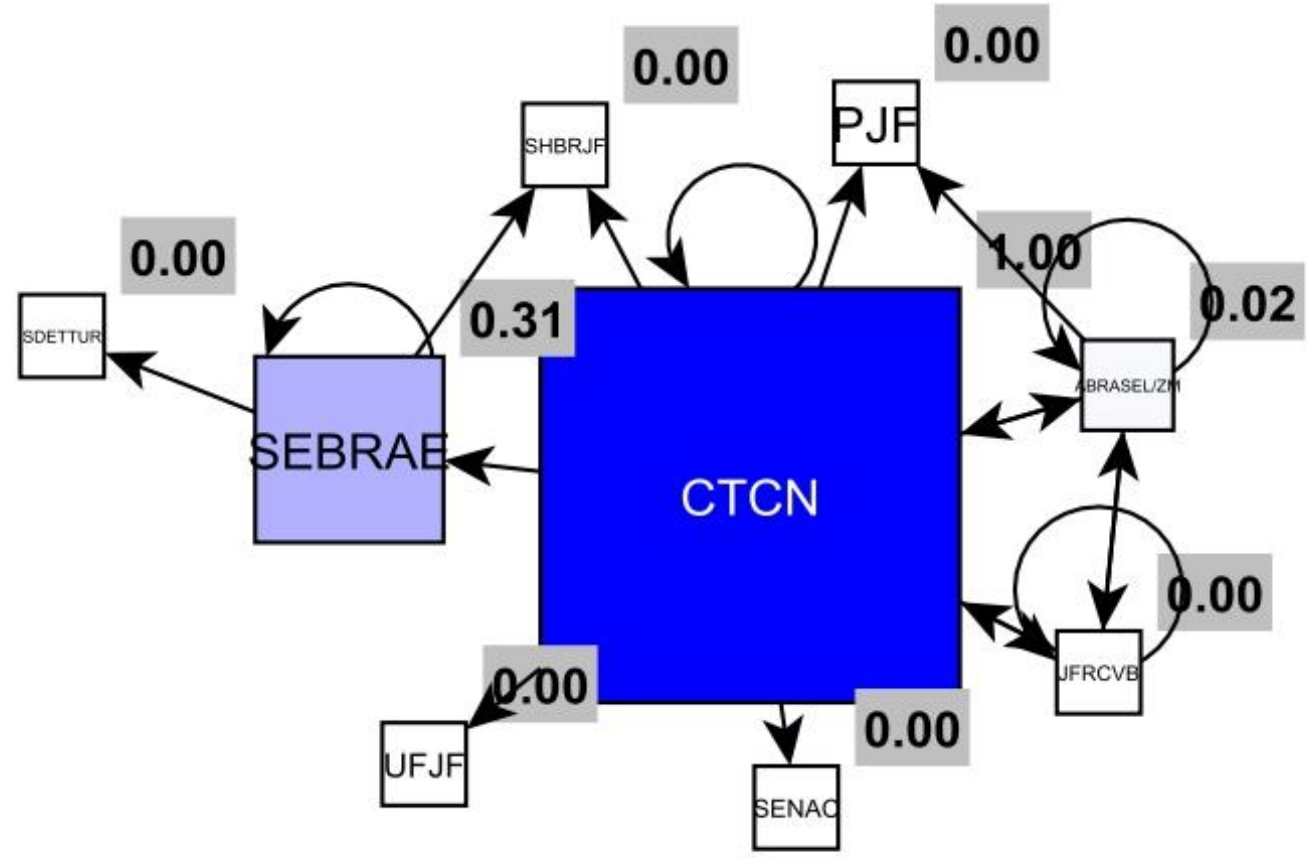

Fonte: Elaboração própria (2017)

Neste caso dessa rede verifica-se apenas duas centralidades - o CTCN e o SEBRAE - com maior funcionalidade, de acordo com o que é apontada pelos índices gerados entre as relações dos atores calculado pela ferramenta de centralidade de intercessão entre nós do software yed (Tabela 02).

Tabela 02 - Índice das instituições da rede apontada

\begin{tabular}{ll}
\hline \multicolumn{1}{c}{ Instituição } & Valor do Índice \\
\hline Circuito Turístico Caminho Novo (CTCN) & 1.00 \\
Serviço de Apoio as Micro e Pequenas Empresas (SEBRAE) & 0.31 \\
Associação Brasileira de Bares e Restaurantes/Zona da Mata Mineira (ABRASEL/ZM) & 0.02 \\
Serviço de Aprendizagem Comercial (SENAC) & 0.00 \\
Prefeitura Municipal de Juiz de Fora (PJF) & 0.00 \\
Universidade Federal de Juiz de Fora (UFJF) & 0.00 \\
Secretaria de Desenvolvimento Econômico, Trabalho e Turismo de Juiz de Fora (SDE- & 0.00 \\
TTUR) & \\
Juiz de Fora e Região Convention Visitors Bureau (JFRC\&VB) & 0.00 \\
Sindicato de Hotéis, Restaurantes, Bares e Similares de Juiz de Fora (SHBRJF) & 0.00 \\
\hline
\end{tabular}
Fonte: Elaboração própria (2017)

Tal fato pode ser observado pelos apontamentos do CTCN que citou em suas respostas um número maior de entidades como importantes para o turismo regional, onde o Circuito foi autocitado. Essa mesma auto indicação foi realizada pela ABRASEL/ZM, JFRCVB e SEBRAE, o que gerou uma volta em sim mesmo para cada delas, ao mesmo tempo em que elas também citam umas às outras. Este comportamento resulta em ligações bidirecionais entre essas entidades e acarretam que a centralidade seja estabelecida pelo CTCN e pelo SEBRAE, reforçando que essas duas instituições exercem maior poder de influência e conexão nessa 
rede. De forma direta a centralidade das instituições ocorre pelo fato do próprio apontamento que elas indicaram, ou seja, quanto maior o número de conexões em uma rede, maior será sua centralidade e seu poder de influenciá-la. No caso da rede apontada pelos próprios agentes do turismo da região, ela se revelou incipiente, pouco complexa e com um número reduzido de conexões, indicando uma certa dependência de toda a região para aquelas duas entidades sediadas em Juiz de Fora.

\subsection{Análise do sociograma da rede possível}

Considerando que as entidades que compõem a rede apontada possuem um conjunto de associados, parceiros e serviços, ao incluí-los na rede temos a possibilidade que haja mais interconexão entre os agentes sociais. Essa questão traz a possibilidade de que tal rede saia de uma condição com laços fortes, fechados, e se abra para uma rede com laços fracos e buracos estruturais que podem agregar a ela novos conhecimentos ao mesmo tempo em que podem manter e desfazer conexões entre os atores. Para tanto foi produzido um sociograma com a 'rede possível' (figura 03) estabelecida entre os agentes sociais e suas principais conexões.

A elaboração deste sociograma da 'rede possível' pode representar graficamente o padrão relacional possível de ser mantido nessa rede social, tendo em vista que o apontamento das entidades foi feito dentro da percepção deles próprios. Com isso, é possível visualizar a centralidade, as interconexões entre agentes e grupos e ainda qual é o potencial de um nó em expandir suas relações de conexão.

Ao inserir ou retirar agentes em uma rede social sua dinâmica se altera na proporção das interferências sofridas nas ligações entre seus nós. 0 sociograma elaborado para a 'rede possível' trouxe um novo desempenho nas conexões entre os atores e direcionou para 276 nós (node) e 309 laços (edges). Porém, quando comparado com o sociograma da 'rede observada' o resultado para os três principais agentes de maior influência se mantiveram equiparados aos índices da 'rede apontada'.

Tal situação demonstra que, mesmo diante de um novo contexto de troca e inserção de outros nós (agentes) na rede, o COMTUR-JF, a ABRASEL/ZM e o JFRC\&VB se mantiveram em posições de maior centralidade e com mais conexões estabelecidas com outros nós e grupos. Os resultados ainda indicam que há uma grande centralização de entidades/instituições do município de Juiz de Fora, indicando esta cidade como polo regional dotada de recursos humanos e institucionais capazes de atingir toda a região. 
Figura 03 - Sociograma da Rede Possível do Circuito Turístico Caminho Novo

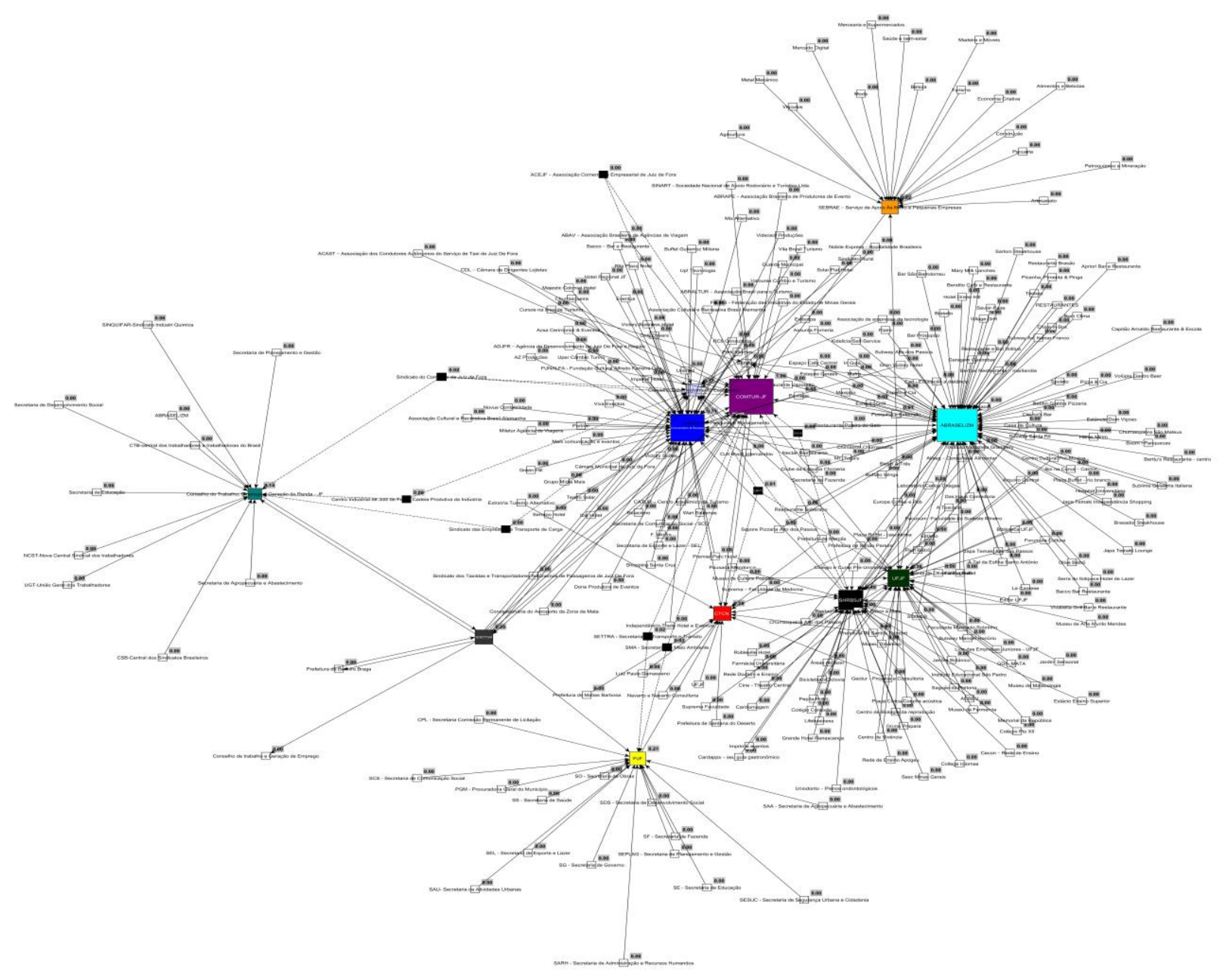

Fonte: Elaboração própria (2017) 
Tabela 03 - Índice das instituições da rede possível

\begin{tabular}{lc}
\multicolumn{1}{c}{ Instituição } & Valor do Índice \\
\hline Conselho Municipal de Turismo de Juiz de Fora (COMTUR-JF) & 1.0 \\
Associação Brasileira de Bares e Restaurante/Zona da Mata Mineira (ABRASEL/ZM) & 0.91 \\
Juiz de Fora e Região Convention \& Visitors Bureau (JFRC\&VB) & 0.71 \\
Sindicato de Hotéis, Restaurantes, Bares e Similares de Juiz de Fora (SHRBSJF) & 0.45 \\
Universidade Federal de Juiz de Fora (UFJF) & 0.36 \\
Secretaria de Desenvolvimento Econômico, Trabalho e Turismo de Juiz de Fora (SDETTUR) & 0.26 \\
Circuito Turístico Caminho Novo (CTCN) & 0.25 \\
Serviço de Apoio As Micro e Pequenas Empresas (SEBRAE) & 0.22 \\
Prefeitura de Juiz de Fora (PJF) & 0.21 \\
Conselho de Desenvolvimento Econômico (CDE-JF) & 0.17 \\
Conselho de Trabalho, Emprego e Geração de Renda de Juiz de Fora (CMGER-JF) & 0.14 \\
Sindicado do Comércio de Juiz de Fora (SINDCOMERCIO-JF) & 0.02 \\
Secretaria de Transporte e Trânsito de Juiz de Fora & 0.02 \\
(SETTRA-JF) & 0.02 \\
Secretaria de Meio Ambiente de Juiz de Fora (SMA-JF) & 0.01 \\
Centro Regional de Inovação e Transferência de Tecnologia da UFJF (CRITT) & 0.00 \\
Demais & \\
\hline
\end{tabular}

Fonte: Elaboração Própria (2017)

De forma geral, a análise do sociograma produzido pela 'rede possível' aponta para deficiências no PRT dentro da rede regional analisada, tendo em vista o baixo índice de centralidade apresentando pela instância de governança do $\operatorname{CTCN}(0,25)$ (Tabela 03) e as poucas conexões estabelecidas por ela. Somente a análise do sociograma isolada já traz uma boa visualização do cenário atual da rede regional, mas sua compreensão pode ser complementada com a análise do conteúdo das informações obtidas junto aos agentes sociais que compõem a rede.

\subsection{Análise de conteúdo das entrevistas dos agentes sociais da região do CTCN}

A terceira etapa do método bola de neve, que embasa esse tópico de análise, foi composta pela aplicação de um questionário, por correio eletrônico, enviado à SETUR-MG e à FECITUR, e pela realização de entrevistas estruturadas com os principais agentes do turismo da região de estudo, selecionados com base nas indicações feitas na segunda rodada. O conjunto de perguntas foi estruturado a partir de quatro variáveis: (a) capacidade dos agentes sociais se articularem em rede; (b) grau de proximidade de relação entre os agentes sociais; (c) nível de capacidade gerencial da região, e (d) formação de redes regionais entre agentes sociais.

Após a coleta dos dados foi elaborado um quadro adaptado de Bardin (2011), para produzir a análise de conteúdo dos questionários e entrevistas. 0 quadro foi dividido em linhas e colunas, inseridos os campos da variável levantada, o entrevistado, a transcrição da fala, palavras chave, e por último uma observação sobre o tema central apontado na fala do entrevistado.

No caso específico da análise das entrevistas dessa pesquisa o conteúdo temático partiu da transcrição das falas correspondentes às variáveis selecionadas previamente, destacando-se, em negrito, o conteúdo principal. A partir disso, foram apontadas palavras-chaves do discurso de cada entrevistado.

\subsubsection{Capacidade dos agentes sociais se articularem em rede}

A variável 'capacidade dos agentes sociais se articularem em rede' buscou a compreensão do comportamento estabelecido entre os envolvidos na rede regional e seu nível de articulação. Dentro de uma perspectiva inter organizacional observou-se se cada instituição tem a capacidade de reconhecer seu papel e do outro, como agentes capazes de se influenciarem e de se articularem em rede. Para tanto, partiu-se do entendimento da complexidade de interrelação mantida entre o poder público, a iniciativa privada e a sociedade civil, nos níveis estadual, regional e municipal.

O conteúdo das entrevistas dessa variável apontou para incompatibilidades, deficiências e conflitos na articulação em rede entre os agentes sociais dessa região. Há falta de diálogo entre as instituições e uma baixa ou nenhuma articulação em rede entre o poder público, iniciativa privada e sociedade civil. Identifi- 
cou-se muito aspectos semelhantes nas falas das entidades no que diz respeito à falta de compreensão do papel de cada uma como agente do turismo, falta de diálogo entre agentes, comportamento de competição em detrimento do trabalho em rede e falta de ligação e de convergência de ações entre o poder público, iniciativa privada e sociedade civil.

Tais posturas negativas presentes na região direcionam para um baixo índice da capacidade de articulação em rede e para um enfraquecimento das políticas públicas de turismo na região, pois trazem consigo um quadro reverso às propostas do trabalho em rede e descentralizado propostos pelas atuais políticas públicas de turismo nacional (PRT) e estadual (Circuitos Turísticos).

\subsubsection{Grau de proximidade de relação entre os agentes sociais}

A variável sobre o 'grau de proximidade de relação entre os agentes sociais', foi considerada a partir do pressuposto de que toda rede se faz a partir de relações, sejam elas interpessoais ou interinstitucionais. Dessa maneira essa variável buscou identificar a proximidade das relações entre os agentes da rede do CTCN, em uma perspectiva regional, mantida entre agentes públicos, privados e da sociedade civil.

Ao se analisar e cruzar o conteúdo das falas observou-se que há uma baixa proximidade de relações, incompreensão sobre os critérios básicos do Programa de Regionalização e pouco investimento nas instâncias de governança; na mesma proporção verificou-se um baixo grau de proximidade entre os agentes sociais na região. Essa visão de baixo grau de interação é indicada pelo próprio órgão estadual (SETURMG) e pelas próprias entidades entrevistadas, que ainda veem como pouco representativo e tímido o grau de relação mantido entre as instituições.

\subsubsection{Formação de redes regionais entre agentes sociais}

Um dos critérios básicos na construção de políticas públicas com foco regional é a implementação do trabalho em rede envolvendo agentes dos setores públicos, privado e sociedade civil. Nesse contexto, essa variável prezou identificar se as entidades/instituições envolvidas no turismo regional conseguem manter relações em rede no intuito promover o desenvolvimento do turismo de forma ampla.

Os apontamentos das instituições entrevistadas indicam uma forte desarticulação entre as instituições públicas e privadas no envolvimento e na participação na formação de redes regionais, o que acaba produzindo uma centralidade em poucas entidades que tentam, de forma tímida, realizar ações em prol do turismo quase sempre focadas em apenas um município, Juiz de Fora. Na fala do CTCN, a entidade aponta duas questões fundamentais que contribuem para a deficiência na formação de redes na região. A primeira tem relação com o estágio atual de entendimento das políticas públicas de turismo por parte dos municípios que sequer ultrapassaram a fase inicial do PNMT (1998) e tentam compor uma região turística. A segunda é com relação a falta de entendimento dos agentes locais e regionais para a necessidade de uma governança regional. O CTCN enfatiza que havendo repasse de recursos surge a possibilidade de realizar um trabalho junto aos municípios para demonstrar como se opera em uma visão regional. Em síntese, observa-se pouco amadurecimento na formação e funcionamento básico da estrutura necessária para se operar o fenômeno turístico dentro de um contexto regional.

\subsubsection{Nivel de capacidade gerencial de uma região turística}

Essa variável foi levantada a partir da estrutura de gestão compartilhada apontada pelo PRT (2013), trabaIhada em niveis de gestão contemplando as esferas nacional, estadual, regional e municipal. Para a escala regional ficou estabelecido à instância de governança como responsável pela gestão do turismo em sua região. A partir desse pressuposto, a variável buscou identificar a percepção dos agentes sociais sobre a gestão desenvolvida dentro do contexto da participação ampla e efetiva de todas as entidades/instituições envolvidas com turismo nessa região turística.

Como ponto prejudicial essa variável apontou para a inexistência de um profissional com dedicação exclusiva para realizar toda a gestão e a parte administrativa do CTCN, considerado extremamente necessário 
para o seu funcionamento e para a execução de projetos e ações de articulação regional. Outro ponto negativo tem relação com a sobreposição de entidades de cunho regional que atuam no turismo, todas centradas em um único município, Juiz de Fora.

Considerando o que apontam os dados coletados, observou-se ruídos no processo de gestão regional influenciados pela incompreensão do papel de cada agente dentro do processo de descentralização. A ponta desse sistema (município) onde as ações das políticas públicas deveriam acontecer de forma mais diretiva acabam sendo deficitárias, derivada da própria ingerência municipal e pela falta de cooperação intermunicipal e interinstitucional que não produzem sinergia em suas decisões.

\section{CONSIDERAÇÕES FINAIS}

Como política pública de turismo a regionalização e a descentralização da gestão tem suas bases nas instâncias de governança regionais, que têm o papel de ser o fórum de discussões direcionadas para gerir, planejar e desenvolver os territórios turísticos a partir da aglutinação de seus municípios e dos agentes que compõem o sistema turístico regional. Nesse contexto, em Minas Gerais o fortalecimento dessas instâncias, compõe a estratégia de planejamento estadual pensada para administrar e produzir resultados eficazes no ordenamento turístico territorial.

A articulação em rede na região do Caminho Novo, objeto dessa pesquisa, demonstrou-se deficitária com um baixo índice de poder de articulação entre os setores público, privado e a sociedade civil regional. Como reflexo disso, o grau de proximidade das relações sofre interferências que precisam ser ajustadas quando o foco é trabalhar com o turismo em nível regional a partir da formação de redes e da gestão descentralizada. No tocante, a densidade dos laços relacionais mantidos entre os agentes sociais incluindo o setor público, privado e sociedade civil, não parece ser suficiente para sustentar e formatar uma rede regional sólida que possa se consolidar para produzir ações sistêmicas nessa região.

No patamar da gestão regional, os entraves financeiros, a baixa participação, a centralização excessiva, o pouco entendimento sobre os critérios das políticas de turismo, a imaturidade para se trabalhar em rede, a inexistência de um gestor executivo, as ingerências municipais, a sobreposição de entidades, podem ser indicadas como causas que convergem e dificultam a capacidade gerencial de uma região turística.

De forma bastante clara, tanto no sociograma da rede observada como naquele da rede possível, o CTCN, que deveria ser o agente com maior centralidade por ser a instância regional, ainda aparece marginalmente e perde seu caráter de agente central. Tal constatação abre precedentes para que outras entidades com atuação regionalizada assumam a centralidade da rede, mas isto não as coloca na condição de interlocutores regionais junto ao Estado, pois suas representatividades se resumem a segmentos específicos dentro do turismo e não contemplam a totalidade do sistema turístico.

As duas análises (sociogramas e análise de conteúdo) realizadas indicaram pontos convergentes que traduzem a atual realidade da gestão do turismo pela instância de governança do Caminho Novo no período dessa pesquisa. Um desses pontos é a inexistência de uma rede regional consolidada que tanto pode ser visualizada nos sociogramas da rede apontada e da rede possível, como também no discurso das entidades entrevistadas.

Na região pesquisada, com base nos dados analisados, o contexto sobre redes sistêmicas interconectadas ainda não foi bem assimilado pelos agentes sociais. Verificam-se ainda comportamentos reducionistas que impossibilitam a interação em redes municipais e regionais e que se distanciam de interações sistêmicas e complexas. Nesse contexto, o turismo como um sistema complexo opera dentro de padrões que influenciam todo o sistema e, qualquer mudança promovida pela implementação de novas políticas públicas produzem uma necessidade natural de auto adaptação, auto regulação, de forma que o sistema precisa se moldar.

Nesse comportamento sistêmico retroagente, o desenvolvimento das políticas públicas nos níveis regional e municipal, segundo apontam os resultados, demonstra-se insuficiente uma vez que ainda não atinge em plenitude a proposta de gestão compartilhada e de tomada de decisões com sinergia de esforços propos- 
tas pelas políticas de turismo. As análises dos dados ainda apontaram para a ingerência municipal e regional que se reproduz dentro de um princípio da descontinuidade da gestão pública, ou seja, há uma constante interrupção de programas e projetos que muitas vezes são substituídos por outros a cada troca de gestão dos poderes executivos locais.

Uma das características que identifica a região do CTCN é a disparidade entre os municípios: de um lado encontra-se uma cidade polo regional - Juiz de Fora - que centraliza uma diversidade de aspectos, e de outro lado há um conjunto de municípios pequenos, desprovidos de estrutura político administrativa adequada e com uma previsão orçamentária anual extremamente reduzida, insuficiente para investimentos e custeio de mão de obra especializada. Mesmo com os elementos culturais e históricos que aglutinam a região, criar condições para a integração regional tem se tornado um grande desafio para os gestores locais e regionais. Entendem-se que fica comprovado um certo distanciamento entre o que as políticas públicas de turismo federal (PRT) e estadual (Circuitos Turísticos) propõem e a realidade dos municípios da região estudada. Para que a instância de governança regional consiga cumprir seu papel de articulador e fomentador do desenvolvimento turístico, torna-se necessário que sejam sanadas as fragilidades das estruturas político administrativas dos municípios que compõem o CTCN.

\section{REFERÊNCIAS}

Aguirre, J. L. (2011). Introducción al Análisis de Redes Sociales. Buenos Aires: Documentos de Trabajo, 82, Centro Interdisciplinario para el Estudio de Políticas Públicas. Disponível em: http://www.pensamientocomplejo.org/docs/files/J.\%20Aguirre.\%20Introducci\%F3n\%20al\%20An\%E1lisis\% 20de\%20Redes\%20Sociales.pdf. Acesso em: 25 jun. 2017.

Baggio, R. (2006). Complex systems, information technologies and tourism: a network point of view. Information Technology and Tourism, vol. 8. p. 15-29. DOI: https://doi.org/10.3727/109830506778193850

Baggio, R. (2008). Symptoms of complexity in a tourism system. Tourism Analysis. 13, p. 1-20. DOI: https://doi.org/10.3727/108354208784548797

Bardin, L. (2011). Análise de Conteúdo. Tradução; Luís Antero Reto, Augusto Pinheiro. São Paulo: Edições 70.

Beni, M. C. (1998). Análise Estrutural do Turismo. (Ed). São Paulo: Senac.

Beni, M. C. \& Moesch, M. M. (2017). A teoria da complexidade e o ecossistema do turismo. Turismo - Visão e Ação, Balneário Camboriú, 19(3), p. 430-457. DOI: https://dx.doi.org/10.14210/rtva.v19n3.p430-457.

Bertalanffy, L. (2009). Teoria Geral dos sistemas: Fundamentos, desenvolvimento, aplicações. Petrópolis: Vozes.

Boullón, R. C. (1990). Planificación del espacio turístico. (2ª ed.) México: Trilhas.

Butt, R. S. (1992). Structural Holes. Cambridge, MA: Harvard University Press.

Fratucci, A. C. (2008), A dimensão espacial nas políticas públicas brasileiras de turismo: as possibilidades das redes regionais de turismo. Niterói-RJ: UFF. 308 f, Tese (doutorado), Programa de Pós-graduação em Geografia, Universidade Federal Fluminense, Niterói-RJ.

Fuentes, M. A. (2015). Métodos e metodologias em Sistemas complexos. In Furtado, B. A., Sakowski, P. A. M., \& Tóvolli, M. H., Modelagem de sistemas complexos para políticas públicas (pp. 65-84). Brasília: IPEA.

Furtado, B. A., Sakowski, P. A. M., \& Tóvolli, M. H. (2015). Abordagem de Sistemas complexos para políticas públicas. In Furtado, B. A., [et al...], Modelagem de sistemas complexos para políticas públicas (pp. 21-42). Brasília: IPEA.

Gentile, J. E., Glazner, Cs \& Koehler, M. (2015). Modelos De Simulação Para políticas públicas. In Furtado, B. A; Sakowski, P. A. M [et al...], Modelagem de sistemas complexos para políticas públicas (pp. 85-96). Brasília: IPEA. 
Granovetter, M. (1973). The strength of weak ties. American Journal of Sociology, Chicago, 78(6), p. 13601380, may. Disponivel em http://links.jstor.org/sici?sici=00029602\%28197305\%2978\%3A6\%3C1360\%3ATSOWT\%3E2.0.CO\%3B2-E. Acesso em: 25 jun. 2017.

Granovetter, M. (1983). The strength of weak ties: a network theory revisited. Sociological Theory, San Francisco, 1(1), p. 201-233. Disponível em: http://garfield.library.upenn.edu/classics1986/A1986E936700001.pdf . Acesso em: 25 jun. 2017. DOI: https://dx.doi.org/10.2307/202051

Guilarducci, B. C. \& Fratucci, A. C. (2016). Teoria dos sistemas complexos e possíveis aplicações nos estudos sobre as políticas públicas de turismo. 2016. In: SEMINÁRIO DA ANPTUR, 15., 2016. [Anais...].,São Paulo. Disponível em https://www.anptur.org.br/anais/anais/files/13/389.pdf. Acesso em: 25 jun. 2017.

Haramein, Nassim. (2015a). Plasm flow interaction simulator. United States Patent: patente $\mathrm{n}^{\circ}$ US 8,933,595 B2. Jan. 13, 2015. Disponivel em https://patents.justia.com/patent/9949355. Acesso em: 25 jun. 2017.

Haramein, Nassim. (2015b). Precision cut high energy crystals. United States Patent: patente $\mathrm{n}^{\circ}$ US 2015/0093571 A1. Apr. 02, 2015. Disponível em https://patents.google.com/patent/US20150093571 . Acesso em: 25 jun. 2017.

Haramein, Nassim \& Hyson, Michael \& Rauscher, E. (2016a). Scale unification \pm a universal scaling law for organized matter. Disponível em: https://www.researchgate.net/publication/242582523 SCALE UNIFICATION A UNIVERSAL SCALING LA W_FOR_ORGANIZED_MATTER. Acesso em: 25 jun. 2017.

Haramein, Nassim \& Rauscher, E. (2016b). Spinors, twistors, quaternions, and the ${ }^{3}$ spacetimetorus topology. Disponivel https://www.researchgate.net/publication/242072127 SPINORS TWISTORS QUATERNIONS AND THE S PACETIMETORUS TOPOLOGY. Acesso em: 25 jun. 2017.

Haramein, Nassim \& Brown, William \& Val Baker, Amira. (2016c). The Unified Spacememory Network: from Cosmogenesis to Consciousness. Journal of NeuroQuantology. Disponível em: https://www.researchgate.net/publication/309681048 The Unified Spacememory Network from Cosm ogenesis to_Consciousness. Acesso em: 25 jun. 2017. DOI: https://doi.org/10.14704/nq.2016.14.4.961

Haramein, Nassim \& Brown, William. (2016d). Unified Physics and the Information Network of Awareness. Disponível

em: https://www.researchgate.net/publication/309680981 Unified_Physics and the Information Network of _Awareness. Acesso em: 25 jun. 2017.

Knupp, M. E. C. G. (2014). Análise de políticas públicas de turismo: uma abordagem metodológica baseada em redes sociais. In Pimentel, T. D....[et.al] (org.). Gestão pública do turismo no Brasil (pp. 285-316). Caxias do Sul/RS: Educs.

Leiper, N. (1979). The framework of tourism: towards a definition of tourism, tourist and the tourist industry. Annals of Tourism research, 6(4), 390-407. DOI: https://doi.org/10.1177/004728758001900184

Lemieux, V. \& Ouimet, M. (2012). Análise Estrutural das redes sociais. (2ª ed.). Lisboa: Instituto Piaget: Trad. Sérgio Pereira.

Marques, E. C. (2006). Redes sociais e poder no Estado Brasileiro: aprendizados a partir das políticas urbanas. Revista Brasileira de Ciências Sociais. São Paulo, 21(60), p. 15-41. DOI: http://dx.doi.org/10.1590/S0102-69092006000100002

Minas Gerais. (2003a). Decreto Estadual n 43.321, de 08/05/2003. Dispõe sobre o reconhecimento dos Circuitos Turísticos e dá outras providências. Disponível em: https://www.almg.gov.br/consulte/legislacao/completa/completa.html?tipo=DEC\&num $=43321 \& a n o=200$ 3. Acesso em: 25 jun. 2017. 
Minas Gerais. (2003b). Secretaria de Estado de Turismo. Resolução $n^{\circ}$ 007/2003. Instituir o Certificado de Reconhecimento dos Circuitos Turísticos de Minas Gerais. Disponível em: http://www.descubraminas.com.br/Upload/Biblioteca/0000094.pdf. Acesso em: 25 jun. 2017.

Mitchell, M. (2009). Complexity: a guided tour. New York: Oxford University Press

Moesch, M. M. (2013). A Origem do Conhecimento, o Lugar da Experiência e da Razão na Gênese do Conhecimento do Turismo. Disponível em: http://www.cet.unb.br/images/documentos/divulgacao/maruska.pdf $\quad$ Acesso em: 25 jun. 2017. DOI:https://doi.org/10.26512/revistacenario.v1i1.15206

Moesch, M. \& Beni, M. C. (2015). Do discurso sobre a ciência do Turismo para a ciência do Turismo. In: SEMINÁRIO DA ANPTUR, 14., 2015. [Anais...]. Natal: Rio Grande do Norte. Pdf n.48 Disponível em: https://www.anptur.org.br/anais/anais/files/12/48.pdf. Acesso em: 25 jun. 2017.

Morin, E. (2000). Ciência com consciência. (4ª ed.). Rio de Janeiro: Bertrand Brasil.

Morin, E. Introdução ao pensamento complexo. (2015). Tradução Eliane Lisboa. (5. Ed.). Porto Alegre: Sulina.

Morin, E. O Método 5: (2002c.). A humanidade da humanidade: a identidade humana. Porto Alegre: Sulina.

Morin, E. O Método 6: Ética. (2011). Porto Alegre: Sulina.

Morin, E. O Método I: (200a). A natureza da natureza. Porto Alegre: Sulina.

Morin, E. O Método IV: (2002b). As ideias. (3ª. ed.). Porto Alegre: Sulina.

Panosso Netto, A., \& Lohmann, G. (2008). Teoria do turismo: conceitos, modelos e sistemas. São Paulo: Aleph.

Rand, W. (2015). Sistemas complexos: conceitos, literatura, possibilidades e limitações. In Furtado, B. A. F...[et.al]. Modelagem de sistemas complexos para políticas públicas. (pp. 43-64). Brasília: IPEA.

Recuero, R., Bastos, M. \& Zago, G. (2015). Análise de redes para mídia social. Porto Alegre: Sulina.

Social Network Analysis Theory and Applications. (2011). Disponível em: https://vdocuments.mx/notavailable-social-network-analysis-theory-andbookos-z1org.html . Acesso em: 25 jun. 2017.

Souza, Q. \& Quandt, C. (2008). Metodologia de análise de redes sociais. In: Duarte, F., Quandt. C. \& Souza, Q. O tempo das redes. (pp. 31-63). São Paulo: Perspectivas.

\section{Informações dos autores}

Bruno Campos Guilarducci

Mestre em Turismo - Universidade Federal Fluminense. Bacharel em Turismo.

Curriculum Lattes: http://lattes.cnpq.br/6827743802948262.

Contribuições: Concepção da pesquisa; revisão da literatura; coleta e análise dos dados, discussão dos resultados.

E-mail: brunoghilarducci@hotmail.com.

ORCID: https://orcid.org/0000-0003-2043-3973

\section{Aguinaldo Cesar Fratucci}

Doutor em Geografia - Universidade Federal Fluminense. Professor e pesquisador do Programa de PósGraduação stricto senso em Turismo da Universidade Federal Fluminense.

Curriculum lattes: http://lattes.cnpq.br/8489517667159662

Contribuições: Concepção da pesquisa; análise dos dados, discussão dos resultados.

E-mail: acfratucci@id.uff.br

ORCID: https://orcid.org/0000-0003-4267-4399 